EESTI NSV TEADUSTE AKADEEMIA TOIMETISED, FUOSIKA * MATEMAATIKA ИЗВЕСТИЯ АҚАДЕМИИ НАУК ЭСТОНСКОП ССР ФИЗИКА * МАТЕМАТИКА PROCEEDINGS OF THE ACADEMY OF SCIENCES OF THE ESTONIAN SSR. PHYSICS * MATHEMATICS

$1984,33,1$

УЛК $621.382,3$

Я. ААРИК, Я. БЕРГМАНН, А. ВНРРО, П. ЛЫУК,

А. РОЗЕНТАЛЬ, В. САММЕЛСЕЛЬГ, Я. ФРИДЕНТАЛ

\title{
НЕПРЕРЫВНАЯ ГЕНЕРАЦИЯ AlGaAsSb/GaSb-ГЕТЕРОЛАЗЕРОВ ПРИ КОМНАТНОЙ ТЕМПЕРАТУРЕ
}

J. AARIK, J. BERGMANN, A. VIRRO, P. LOUK, A. ROSENTAL, V. SAMMELSELG, J. FRIEDENTHAL. AIGaAsSb/GaSb-HETEROLASERITE ALALISKIIRGUS TOATEMPERATUURIL

J. AARIK, J. BERGMANN, A. VIRRO, P. LOUK, A. ROSENTAL, V, SAMMELSELG, J. FRIEDENTHAL. ROOM TEMPERATURE CONTINUOUS WAVE OPERATION OF AIGaAsSb/GaSb HETEROSTRUCTURE - LASERS

\section{(Представил К. К. Ребане)}

Непрерывный режим генерации инжекционных лазеров на основе гетероструктур AlGaAsSb/GaSb $\left[{ }^{1-8}\right]$ при комнатной температуре, несмотря на довольно долгое их исследование, не был достигнут. Это было связано либо с трудностями создания структур с тонкими активными слоями $\left[{ }^{1-5,7}\right]$, либо с трудностями согласования параметров решеток твердого раствора $\mathrm{Al}_{x} \mathrm{Ga}_{1-x} \mathrm{As}_{y} \mathrm{Sb}_{1-y}$ и антимонида галлия [ $\left.{ }^{6,8}\right]$. Чтобы обеспечить в двусторонних гетероструктурах электронное и оптическое ограничение, достаточное для надежной работы инжекционных лазеров при комнатной температуре, широкозонные слои структуры должны иметь $x \geqslant 0,2$. В случае применения жидкостной эпитаксии изопериодичности таких слоев с антимонидом галлия можно достичь лишь при температурах эпитаксии .выше $520^{\circ} \mathrm{C}$. Долгое время нерешенной проблемой оставалось получение тонких. слоев при этих температурах. В ходе данной работы нам удалось показать, что в условиях точного подбора как температурных режимов эпитаксии, так и композиций расплавов можно воспроизводимо выращивать гетероструктуры с толщинами активной области до 0,2 мкм даже при $570{ }^{\circ} \mathrm{C}$. В результате впервые созданы инжекционные лазеры в системе $\mathrm{AlGaAsSb/GaSb}$, работающие в непрерывном режиме при комнатной температуре.

Лазерные гетероструктуры были выращены при температурах около $570{ }^{\circ} \mathrm{C}$. В качестве подложечного материала использовался антимонид галлия, легированный кремнием. На подложках с ориентацией (100) последовательно выращивались эмиттер из $p-\mathrm{Al}_{0,3} \mathrm{Ga}_{0.7} \mathrm{As}_{0,02} \mathrm{Sb}_{0,98}$, активная область из $p$-GaSb, эмиттер из $n$ - $\mathrm{Al}_{0,3} \mathrm{Ga}_{0,7} \mathrm{As}_{0,02} \mathrm{Sb}_{0,98}$ и приконтактный слой из $n$-GaSb. Эмиттер p-типа был легирован германием, а $n$-эмиттер и приконтактный слой - теллуром. Активную область преднамеренно не легировали. Толщины слоев составляли $2,0,2-0,4,2$ и 1 мкм соответственно.

Лазеры с широкими контактами, изготовленные из этих структур, имели пороговую плотность тока $2,1 \mathrm{kA} / \mathrm{cm}^{2}$ в импульсном режиме при 300 K. В этих же условиях минимальные пороговые токи лазеров с мелкой мезаполоской составляли 200-250 мА при ширине полоски 18 и длине резонатора 200-300 мкм. Температурную зависимость порогового тока $J_{\text {II }} \sim \exp \left(T / T_{0}\right)$ при комнатной температуре характеризовал пока- 


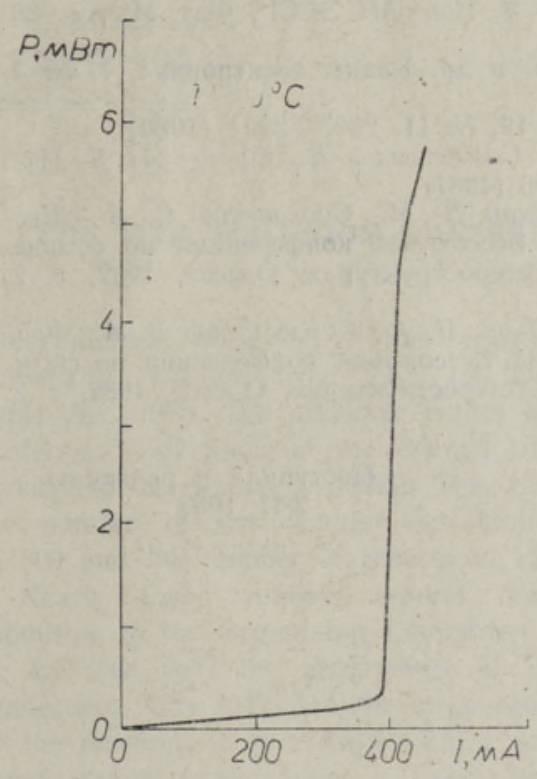

Рис. 1. Ваттамперная характеристика непрерывного мезаполоскового $\mathrm{AlGaAsSb} / \mathrm{GaSb}$-гетеролазера. Длина резонатора 310 , ширнна полоски 18 мКм.
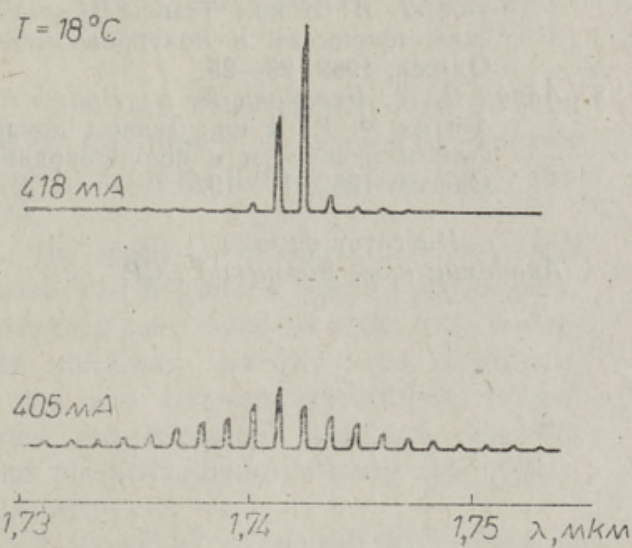

Рис. 2. Спектры излучения непрерывного мезаполоскового AlGaAsSb/GaSb-гетеролазера (порог генерации 395 мA).

затель экспоненты $T_{0}=67 \mathrm{~K}$. Минимальный пороговый ток полоскового лазера в непрерывном режиме равнялся 280 мА. Длина волны непрерывной генерации при комнатной температуре составляла $1,74-1,77$ мкм.

Ваттамперная характеристика, и спектры излучения лазера с длиной резонатора 310 мкм представлены на рис. 1 и 2 соответственно. Как видно из рис. 1, ваттамперная характеристика линейна до выходной мощности 5 мВт. Отметим, что максимальная мощность излучения с одного торца в непрерывном режиме превышала 10 мВт.

Излучение имело ТЕ-поляризацию.

По смещению длины волны непрерывной генерации относительно длины волны генерации в импульсном режиме была определена температура активной области лазера, которая составляла $350 \mathrm{~K}$. Этот результат показывает, что лазеры с активной областью из антимонида галлия способны работать в непрерывном режиме при температурах, значительно превышающих комнатные. Таким образом, на наш взгляд, полностью доказана практическая применимость неохлаждаемых инжекционных $\mathrm{AlGaAsSb} / \mathrm{GaSb}$-лазеров.

В заключение авторы выражают свою искреннюю благодарность K. К. Ребане за постоянный интерес,к данной работе, П. Г. Елисееву, М. Г. Мильвидскому, Л. М. Долгинову и Л. В. Дружининой за полезные дискуссии, Е. Асари и Х. Келле за проведение электронно-зондовых исследований и Р. Гайлит, Э. Карм, К. Каск, Э. Куус и Л. Парис за помощь при изготовлении лазерных гетероструктур.

\section{ЛИТЕР А Т У Р А}

1. Долгинов Л. М., Дружинина Л. В., Елисеев П. Г., Мильвидский М. Г., Свердлов Б. Н. Квант. электроника, 3, № 2, 465-466 (1976).

2. Law, H. D., Harris, J. S. Jr., Wong, K. C., Tomasetta, L. R. In: GaAs and Related Compounds, 1978. Institute of Physics Conference Series, № 45; London, 1979, $420-428$. 
3. Аарик Я., Бергманн Я., Льук П., Фридентал Я. Изв. АН ЭССР, Физ. Матем., 29, № 2, 217-220 (1980).

4. Аарик Я. А., Долгинов Л. М., Дракин А. Е. и др. Квант. электроника, 7, № 1, $91-96(1980)$.

5. Motosugi, G., Kagawa, T. Jap. J. Appl. Phys., 19, № 11, 2303-2304 (1980).

6. Аарик Я., Бергманн Я., Вирро А., Лыук П., Саммелсельг В., Фридентал Я. Изв. АН ЭССР, Физ. Матем., 30, № 4, 395-396 (1981).

7. Адливанкин А. С., Жуков Н. Д., Райгородский В. М., Сосновский С. А., Шестак Л. И. В кн.: Тезисы докладов III Всесоюзной конференции по физическим процессам в полупроводниковых гетероструктурах, Одесса, 1982, т. 2, Одесса, 1982, 23-25.

8. Аарик Я. А., Бергманн Я. В., Вирро А. Л., Лыук П. А., Саммелсельг В. А., Фридентал Я. К. В кн.: Тезисы докладов III Всесоюзной конференции по физическим процессам в полупроводниковых гетероструктурах, Одесса, 1982, т. 2. Одесса, 1982, 17-19.

Институт физики

Академии наук Эстонской ССР
Поступила в редакцию $2 /$ II 1983 